\title{
Highly efficient Yb-free Er-La-Al doped ultra- low NA large mode area single-trench fiber laser
}

\author{
D. Jain,* S. Alam, Y. Jung, P. Barua, M. N. Velazquez, and J. K. Sahu \\ Optoelectronics Research Center, University of Southampton, Southampton SO17 1BJ, United Kingdom \\ *dj3g11@orc.soton.ac.uk
}

\begin{abstract}
We demonstrate a $60 \mu \mathrm{m}$ core diameter $\mathrm{Yb}$ free Er-La-Al doped single-trench fiber having a 0.038 ultra-low-NA, fabricated using conventional MCVD process in conjunction with solution doping technique. Numerical simulations predict an effective single mode operation with effective area varying from $1,820 \mu \mathrm{m}^{2}$ to $1,960 \mu \mathrm{m}^{2}$ (taking bend-induced modal distortion into account) for different thicknesses of trenches and resonant rings at a constant bend radius of $25 \mathrm{~cm}$. Moreover, all solid structure favors easy cleaving and splicing. Experimental measurements demonstrate a robust effective single mode operation. Furthermore, with a $4 \%-4 \%$ laser cavity, this fiber shows a record efficiency of $46 \%$ with respect to the absorbed pump power.
\end{abstract}

C2015 Optical Society of America

OCIS codes: (140.3510) Lasers, fiber; (060.2410) Fibers, erbium; (060.2280) Fiber design and fabrication; (060.2290) Fiber materials.

\section{References and links}

1. Y. Jeong, S. Yoo, C. A. Codemard, J. Nilsson, J. K. Sahu, D. N. Payne, R. Horley, P. W. Turner, L. Hickey, A. Harker, M. Lovelady, and A. Piper, "Erbium: Ytterbium codoped large-core fiber laser with 297-W continuouswave output power," IEEE J. Sel. Top. Quantum Electron. 13(3), 573-579 (2007).

2. G. P. Agrawal, Nonlinear Fiber Optics, 4th ed. (Academic, 2007).

3. J. C. Jasapara, M. J. Andrejco, A. DeSantolo, A. D. Yablon, Z. Vrallyay, J. W. Nicholson, J. M. Fini, D. J. DiGiovanni, C. Headley, E. Monberg, and F. V. DiMarcello, "Diffraction-limited fundamental mode operation of core-pumped very-large-mode-area Er fiber amplifiers," IEEE J. Sel. Top. Quantum Electron. 15(1), 3-11 (2009).

4. M. Dubinskii, V. Ter-Mikirtychev, J. Zhang, and I. Kudryashov, "Yb-free, SLM EDFA: comparison of 980,1470- and 1530nm excitation for the core- and clad-pumping," Proc. SPIE 6952, 695205 (2008).

5. V. Kuhn, D. Kracht, J. Neumann, and P. Weßels, "67 W of output power from an Yb-free Er-doped fiber amplifier cladding pumped at $976 \mathrm{~nm}$," IEEE Photonics Technol. Lett. 23(7), 432-434 (2011).

6. L. V. Kotov, M. E. Likhachev, M. M. Bubnov, O. I. Medvedkov, M. V. Yashkov, A. N. Guryanov, J. Lhermite, S. Février, and E. Cormier, "75 W 40\% efficiency single-mode all-fiber erbium-doped laser cladding pumped at 976 nm," Opt. Lett. 38(13), 2230-2232 (2013).

7. L. Kotov, M. Likhachev, M. Bubnov, O. Medvedkov, D. Lipatov, A. Guryanov, K. Zaytsev, M. Jossent, and S. Février, "Millijoule pulse energy 100-nanosecond Er-doped fiber laser," Opt. Lett. 40(7), 1189-1192 (2015).

8. J. W. Nicholson, J. M. Fini, A. M. DeSantolo, X. Liu, K. Feder, P. S. Westbrook, V. R. Supradeepa, E. Monberg, F. DiMarcello, R. Ortiz, C. Headley, and D. J. DiGiovanni, "Scaling the effective area of higher-order-mode erbium-doped fiber amplifiers," Opt. Express 20(22), 24575-24584 (2012).

9. C. Jauregui, J. Limpert, and A. Tunnermann, "High-power fiber lasers," Nat. Photonics 7(11), 861-867 (2013) (Invited).

10. D. Jain, C. Baskiotis, and J. K. Sahu, "Mode area scaling with Multi-trench rod-type fibers," Opt. Express 21(2), $1448-1455$ (2013).

11. V. Khitrov, V. V. Shkunov, D. A. Rockwell, Y. A. Zakharenkov, and F. Strohkendl, "Er-doped high-aspect-ratio core rectangular fiber producing $5 \mathrm{~mJ}, 13 \mathrm{~ns}$ pulses at $1572 \mathrm{~nm}$," Opt. Lett. 37(19), 3963-3965 (2012).

12. D. Jain, Y. Jung, P. Barua, S. Alam, and J. K. Sahu, "Demonstration of ultra-low NA rare-earth doped step index fiber for applications in high power fiber lasers," Opt. Express 23(6), 7407-7415 (2015).

13. D. Jain, Y. Jung, M. Nunez-Velazquez, and J. K. Sahu, "Extending single mode performance of all-solid largemode-area single trench fiber," Opt. Express 22(25), 31078-31091 (2014). 


\section{Introduction}

Erbium-doped fiber lasers emitting around $\sim 1550 \mathrm{~nm}$ are important tools for several applications such as free-space communications, light detection and ranging (LIDAR), and remote sensing thanks to the eye-safe nature of this waveband. However, Er-doped fiber laser has not reached the similar performance in terms of output power scaling as its counterpart $\mathrm{Yb}$-doped fiber lasers. $\mathrm{Er}^{3+}$ has poor absorption cross-section at $980 \mathrm{~nm}$ [1], where the high power multimode laser diodes are readily available. In order to address this issue, researchers have used $\mathrm{Yb}$ codoping in phosphosilicate host [1]. Output power level of 100s of watt has been achieved, however output suffers from significant parasitic lasing around 1060nm [1]. Moreover, presence of ytterbium and phosphorous increases the refractive index of the core and precludes the achievement of large mode area (LMA) required to address non-linear effects [2]. One solution to this problem is to use $\mathrm{Yb}$ free Er-doped fiber with resonant pumping near $\sim 1480 \mathrm{~nm}$, which can be useful to generate high peak power pulses with moderate average output power due to the unavailability of high power pump diodes $[3,4]$. Moreover, pumping at $\sim 1480 \mathrm{~nm}$ leads to an overall poor electrical to optical efficiency.

Recently, the output power level of $\mathrm{Yb}$-free Er doped fibers has been scaled up to $75 \mathrm{~W}$ by pumping at $\sim 975 \mathrm{~nm}$ and using reduced core to clad diameter, a $42 \%$ slope efficiency with respect to absorbed pump power at $975 \mathrm{~nm}$ was also reported [4-7]. However, reported core diameter of fibers is smaller than $36 \mu \mathrm{m}$ to ensure effective single mode operation (ESM), which can restrict peak power scaling in pulsed operation [4-7]. Jasapara et al. have demonstrated a $70 \mu \mathrm{m}$ core diameter multi-moded step index fiber (SIF) for peak power scaling achieving an effective area $\left(\mathrm{A}_{\mathrm{eff}}\right)$ of $1,760 \mu \mathrm{m}^{2}$ at $50 \mathrm{~cm}$ bend diameter [3]. However, in order to ensure an ESM operation, special care had to be taken to adiabatically transform the single mode output of a $1480 \mathrm{~nm}$ Raman pump laser in the multi-moded SIF to have a perfect overlap with the signal mode. Thus this technique relies upon a high-brightness pump source which further limits the average power scaling.

From the above discussion, it can be concluded that there is a clear need for an Er-only doped LMA fiber compatible with cladding pumping. Therefore the core composition and core to cladding diameter ratio should be chosen in such a way that a high absorption at pump wavelength (such as $980 \mathrm{~nm}$ or $1480 \mathrm{~nm}$ ) can be achieved without quenching of Er ions so that the device length can be minimized while a high slope efficiency can be achieved. Unfortunately, due to detrimental bend-induced modal distortion, it is not possible to scale the effective area considerably larger than $\sim 1,800 \mu \mathrm{m}^{2}$ with a practical bend diameter of $\sim 50 \mathrm{~cm}$. However, emerging techniques such as amplification of higher order modes (HOMs) [8], keeping fiber straight in the form of rod-type fibers [9,10], and using rectangular core fibers known as HARC or SHARC [11] can be used to scale mode area, but they are still in developing stages.

Recently, we have successfully demonstrated Yb-doped ultra-low NA single trench fiber (STF) for mode area scaling at $1 \mu \mathrm{m}[12,13]$. STF can achieve ESM for mode area as large as $1,000 \mu \mathrm{m}^{2}$ to $1,500 \mu \mathrm{m}^{2}$ at $\sim 40 \mathrm{~cm}$ bend diameter. We achieved an ultra-low-NA rare earth doped core $(\sim 0.038)$ with a resonant ring surrounding the core which effectively couples out the HOMs in the core. In this paper, we present a $60 \mu \mathrm{m}$ core diameter ultra-low NA Yb free Er-La-Al doped single-trench fiber fabricated by conventional MCVD process and solution doping process. Numerical simulations ensure an effective area exceeding $1,820 \mu \mathrm{m}^{2}$ at $50 \mathrm{~cm}$ bend diameter, while maintaining a single mode operation and validated by experimental measurements. Our optimized composition of Er-La-Al leads to a record slope efficiency of $\sim 46 \%$ with respect to absorbed pump power at $975 \mathrm{~nm}$.

\section{Ultra-low NA STF}

Figure 1 presents the schematic of a STF [13]. A STF is constituted of an additional high index ring surrounding the core of a SIF. The low index ring between core and high index 
ring has the same refractive index as that of the cladding and is known as trench. The high index ring has the same refractive index as that of the core and is known as resonant ring. Figure 1 also shows the notations used in this paper: $r_{c}$ is the core radius, $t$ is the thickness of the low-index ring (trench), $\mathrm{d}$ is the thickness of the high-index ring (resonant ring), and $\Delta \mathrm{n}$ is the refractive index difference between the core (or resonant ring) and the trench (or outer cladding).

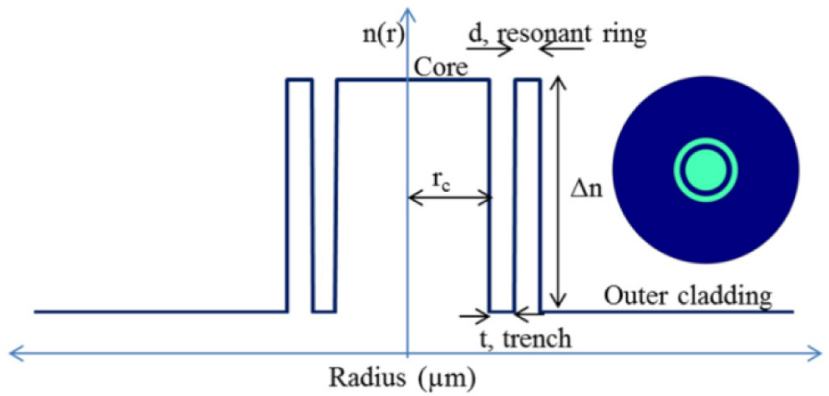

Fig. 1. schematic of refractive index profile of the STF. Inset shows the schematic of crosssection of the STF. Green and blue colour shades represent high and low-refractive index regions respectively.

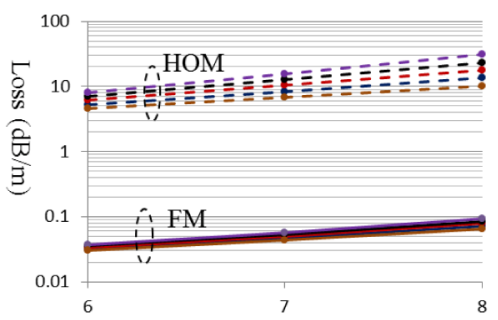

(a) Resonant ring thickness $(\mu \mathrm{m})$

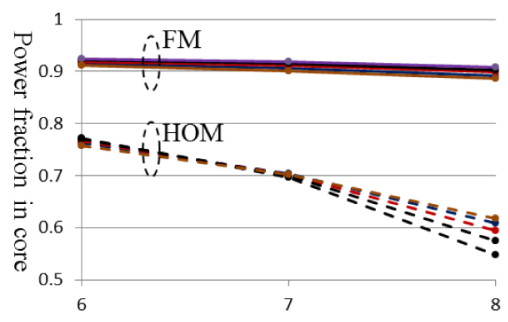

(b) Resonant ring thickness $(\mu \mathrm{m})$

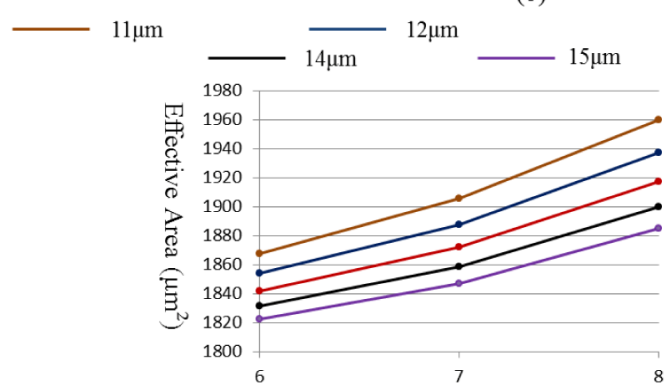

(c) Resonant ring thickness $(\mu \mathrm{m})$

Fig. 2. (a) confinement loss, (b) power fraction in the core for FM and least lossy HOM for different thicknesses of trenches and resonant rings of a $60 \mu \mathrm{m}$ core diameter STF having a 0.038 NA coiled at $25 \mathrm{~cm}$ bend radius, and (c) $\mathrm{A}_{\text {eff }}$ of the fundamental mode. Legends represent the trench thickness.

STF can ensure an ESM operation by offering resonant coupling of the HOMs thanks to the ultra-low NA and resonant ring surrounding the core. The detailed working principle of STF has been explained in a previous report [13]. Here we optimized the thicknesses of the resonant ring and the trench of a STF to ensure an ESM operation at $1550 \mathrm{~nm}$ wavelength band for a fixed core diameter of $60 \mu \mathrm{m}$ with $0.038 \mathrm{NA}$ and at $25 \mathrm{~cm}$ bend radius. The numerical simulations were done using an FEM based COMSOL software. The details of perfectly matched layer (PML) and bend-induced perturbations can be found in reference [13]. 
Figure 2(a) and 2(b) show the numerically computed loss and power fraction in the core respectively for the fundamental mode (FM) and the least lossy higher order mode (HOM) among all the possible HOMs, for different resonant rings and trench thicknesses for a core diameter of $60 \mu \mathrm{m}$ with $\Delta \mathrm{n}=0.0005$ and bend radius of $25 \mathrm{~cm}$ at $1550 \mathrm{~nm}$. Figure $2(\mathrm{c})$ shows the effective area of the $\mathrm{FM}$, which varies from $1,820 \mu \mathrm{m}^{2}$ to $1,960 \mu \mathrm{m}^{2}$ for different thicknesses of the resonant ring and the trench (taking bend-induced modal distortions into account). Other HOMs have loss higher than $70 \mathrm{~dB} / \mathrm{m}$ and are not shown here.

\section{Fiber fabrication}

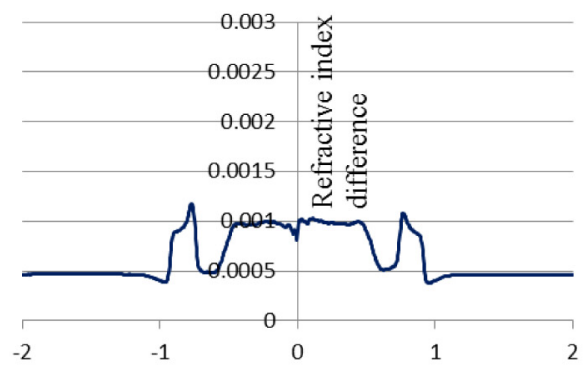

(a) Preform diameter ( $\mathrm{mm})$

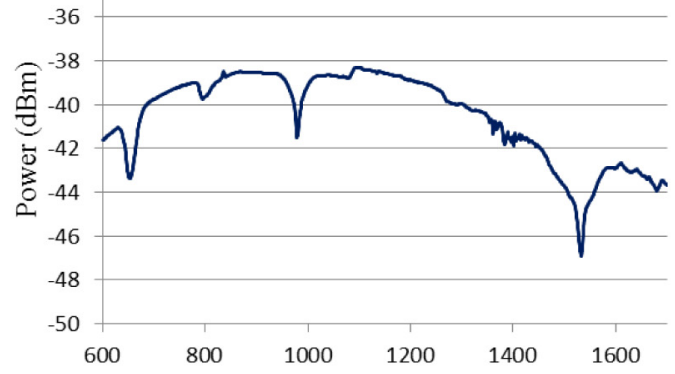

(b) Wavelength (nm)

Fig. 3. (a) measured refractive index profile of Er-La-Al doped preform (b) white light spectrum of a $2.44 \mathrm{~m}$ long fiber.

A preform was fabricated using MCVD process in conjunction with solution doping process. We have used the similar recipe to fabricate this preform as that used for Yb-doped STF $[12,13]$. A flat refractive index profile was obtained as shown in Fig. 3(a). The outer diameter of the preform is $\sim 12 \mathrm{~mm}$. First, a fiber with $600 \mu \mathrm{m}$ outer diameter was drawn, leading to a $\sim 50 \mu \mathrm{m}$ core diameter. However, large clad to core diameter ratio resulted in poor cladding absorption. In order to increase the cladding pump absorption, preform was etched down to $4 \mathrm{~mm}$, milled to D-shape to promote pump mode mixing and finally drawn into $240 \mu \mathrm{m}$ outer diameter fiber with low index polymer coating leading to a $60 \mu \mathrm{m}$ core diameter. Figure $3(\mathrm{~b})$ shows the white light absorption spectrum of a $2.44 \mathrm{~m}$ long fiber. The cladding absorption of the fiber at $975 \mathrm{~nm}$ and $980 \mathrm{~nm}$ are $0.74 \mathrm{~dB} / \mathrm{m}$ and $1.14 \mathrm{~dB} / \mathrm{m}$ respectively.

\section{Experimental characterization}

Figure 4(a) shows the experimental setup used for the verification of single mode behavior of $50 \mu \mathrm{m}$ STF. A $2 \mathrm{~m}$ long fiber was used for the characterization work. We stripped a small section of low index polymer coating from both ends of the fiber and applied index matching oil to strip out cladding modes. Due to high absorption at $\sim 1550 \mathrm{~nm}$, we use a $1570 \mathrm{~nm}$ signal source for modal characterization. Figure 4(b) shows the CCD image of the output beams when $\mathrm{LP}_{01}$ mode was launched into the $2 \mathrm{~m}$ long fiber at various offset launch conditions. Despite a slight change in intensity profile the output beam remains Gaussian irrespective of launch conditions. Figure 4(c) shows the profile of the input beams used to further test the ESM behavior of the fiber. No light was detected at the output confirming the high suppression of the higher order modes. 


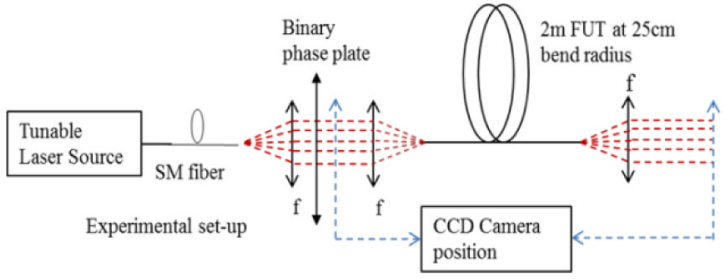

(a) (b)

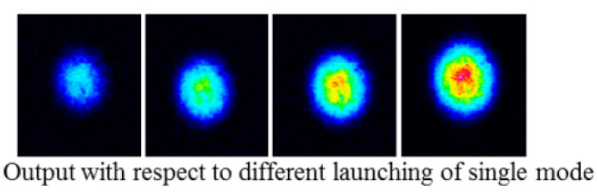

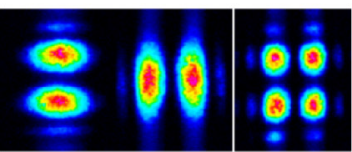

(c) Input beam

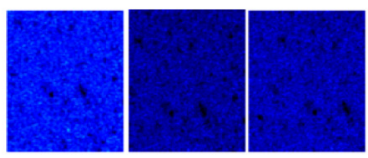

(d) Output beam

Fig. 4. (a) experimental setup for single mode verification, (b) profile of the output beam with respect to different offset launching of the $\mathrm{LP}_{01}$ mode, (c) profile of the input beams used to test ESM behavior, and (d) profile of the output beams when various higher order modes are launched. A $2 \mathrm{~m}$ long $50 / 600 \mu \mathrm{m}$ fiber coiled at $25 \mathrm{~cm}$ bend radius was used as fiber under test (FUT) in this experiment. The wavelength of the laser source is $1570 \mathrm{~nm}$.

We have also examined the $60 \mu \mathrm{m}$ core diameter $(240 \mu \mathrm{m}$ outer diameter) fiber using the same experimental setup. Once again a $2 \mathrm{~m}$ long fiber was used for the detailed characterization. Figure 5(b) shows the CCD images of the output beams when $\mathrm{LP}_{01}$ mode was launched. Wavelength scanning from $1500 \mathrm{~nm}$ to $1620 \mathrm{~nm}$ shows that non-Gaussian output changes to Gaussian output with increasing wavelengths. No profiles can be detected between 1520 and $1560 \mathrm{~nm}$ due to high Er-absorption within this wavelength range. Figure 5(c) shows profile of the two input beams used to validate ESM behavior while Fig. 5(d) shows the corresponding output profiles. As there is little output for the $\mathrm{LP}_{11}$ input compared to $\mathrm{LP}_{01}$ input, this custom made fiber is able to provide a relatively high discrimination for the $\mathrm{LP}_{11}$ and other higher order modes. We have also tried offset launching of the $\mathrm{LP}_{01}$ mode but the output remained Gaussian. These measurements clearly demonstrate robust ESM operation of the fabricated fiber, however measurements confirms a $50 \mu \mathrm{m}$ fiber to more robust than a $60 \mu \mathrm{m}$ fiber.
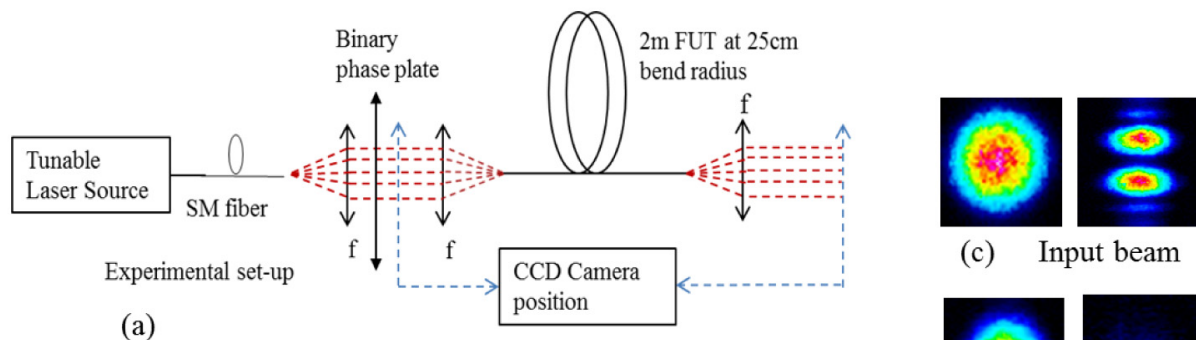

(c) Input beam

(a)

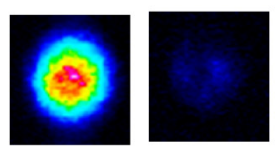

(d) Output beam

(b)

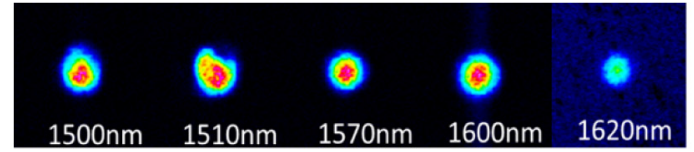

Fig. 5. (a) experimental setup for single mode verification, (b) profile of the output beams with respect to $\mathrm{LP}_{01}$ mode launch at different wavelengths, (c) profile of the input beams used to test the ESM behavior, and (d) profile of the output beams for different launched mode at $1570 \mathrm{~nm}$. A $2 \mathrm{~m}$ long $60 / 240 \mu \mathrm{m}$ fiber coiled at $25 \mathrm{~cm}$ bend radius was used in this experiment. 


\section{Laser efficiency measurement}

In order to verify the laser performance of the fabricated fiber, we tested the fiber in a simple $4 \%-4 \%$ laser cavity. We used a $10 \mathrm{~m}$ long $60 / 240 \mu \mathrm{m}$ fiber coiled at $\sim 50 \mathrm{~cm}$ bend diameter. Although the fiber shows a relatively higher absorption coefficient at 980nm (see Fig. 3(b)) but due to the unavailability of a suitable pump source at this wavelength we were forced to use a pump module operating at $975 \mathrm{~nm}$ which compromises the overall pump absorption and hence the maximum achievable average output power. Figure 6(a) shows the measured slope efficiency with respect to absorbed pump power at $975 \mathrm{~nm}$. The slope efficiency is estimated to be $46.3 \%$. To the best of our knowledge, this is the highest efficiency ever reported for a $\mathrm{Yb}$-free Er-doped fiber laser pumped at 9xxnm wavelength band. Figure 6(b) shows the spectrum of the free running laser. A maximum output power of $\sim 12 \mathrm{~W}$ was obtained at $\sim 28 \mathrm{~W}$ of absorbed pump power, while the pump throughput was measured to be $\sim 53 \mathrm{~W}$. Further power scaling was primarily limited by the low overall pump absorption as well as the available pump power. It may be possible to scale the average output power by using a longer device length. However, optimizing the composition of $\mathrm{Er}, \mathrm{Al}$, and $\mathrm{La}$ and decreasing the core to clad diameter ratio might open the doors of higher slope efficiency and consequently a higher average output power.
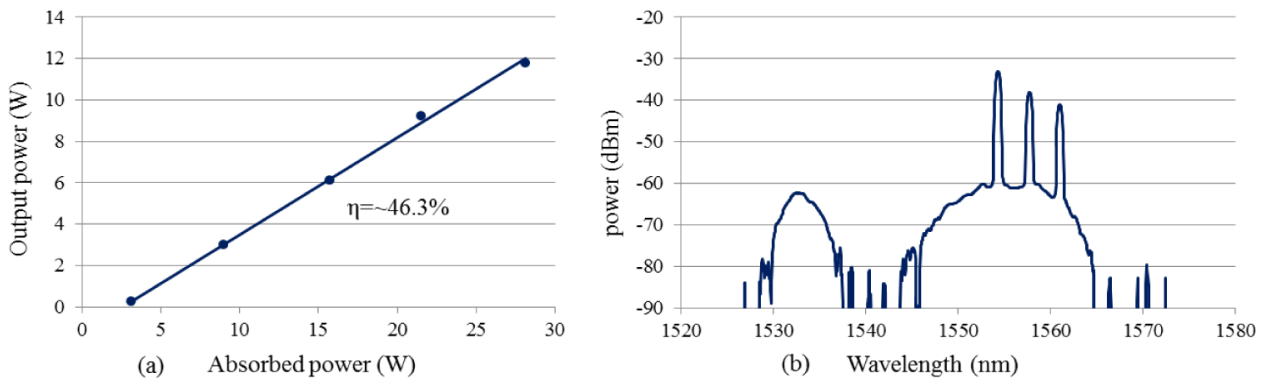

Fig. 6. (a) Average output power from a $10 \mathrm{~m}$ long Er-La-Al doped STF with respect to absorbed pump power in a $4 \%-4 \%$ laser cavity (b) spectrum of the free running laser at the highest output power.

\section{Conclusion}

In conclusion, we have demonstrated an $\mathrm{Yb}$ free Er-La-Al doped STF with $60 \mu \mathrm{m}$ core diameter and ultra-low NA showing an ESM operation at $1550 \mathrm{~nm}$. The fiber exhibits a high slope efficiency of $\sim 46 \%$ in a $4 \%-4 \%$ laser cavity. To the best of our knowledge, this is the simplest large mode area fiber ever reported at $1550 \mathrm{~nm}$ with such a high efficiency. Moreover, all solid structure favors easy post processing of fiber such as cleaving and splicing.

\section{Acknowledgement}

The work is supported by the EPSRC Centre for the Innovative manufacturing in Photonics $\mathrm{EP} / \mathrm{HO} 2607 \mathrm{X} / 1$. The data for this work is accessible through the University of Southampton Institutional Research Repository (DOI: 10.5258/SOTON/382676). 